Revue bibliographique pour le domaine irano-aryen

\title{
Michele Minardi, Alison V. G. Betts, Gairatdin Khozhaniyazov. "Columned Halls in Ancient Chorasmia"
}

\section{Astrid Nunn}

\section{(2) OpenEdition Journals}

Édition électronique

URL : http://journals.openedition.org/abstractairanica/48834

DOI : $10.4000 /$ abstractairanica.48834

ISBN : 1961-960X

ISSN : 1961-960X

Éditeur :

CNRS (UMR 7528 Mondes iraniens et indiens), Éditions de l'IFRI

\section{Référence électronique}

Astrid Nunn, « Michele Minardi, Alison V. G. Betts, Gairatdin Khozhaniyazov. "Columned Halls in Ancient Chorasmia" », Abstracta Iranica [En ligne], Volume 40-41 | 2019, document 14, mis en ligne le 30 octobre 2019, consulté le 23 avril 2021. URL : http://journals.openedition.org/abstractairanica/ 48834 ; DOI : https://doi.org/10.4000/abstractairanica.48834

Ce document a été généré automatiquement le 23 avril 2021.

Tous droits réservés 


\title{
Michele Minardi, Alison V. G. Betts, Gairatdin Khozhaniyazov. "Columned Halls in Ancient Chorasmia"
}

\author{
Astrid Nunn
}

\section{RÉFÉRENCE}

Michele Minardi, Alison V. G. Betts, Gairatdin Khozhaniyazov. "Columned Halls in Ancient Chorasmia", Iran, 55/2, 2017, p. 208-226

1 La Chorasmie, en Ouzbekistan actuel, contient de nombreux sites fortifiés entre le VI ${ }^{\mathrm{ème}}$ s. av. J.-C. et le II ème s. ap. J.-C. Certains bâtiments y sont même assez monumentaux, aussi bien en taille que dans leur agencement comparable avec des grands halls ou des salles à colonnes. Les A. travaillent sur le site de Akchakhan-kala, ancienne résidence royale qui leur sert de point de départ et de référence pour leur étude sur les halls à colonnes dans cette région.

2 La salle hypostyle de Akchakhan-kala, située dans le «Central Building », mesure $19 \mathrm{x}$ $14 \mathrm{~m}$ et compte douze colonnes. Celles-ci reposent sur différents types de bases, carrée ou arrondies. La salle étant ouverte sur une cour, les A. supposent qu'elle est liée au cérémonial royal. La salle hypostyle la plus ancienne en Chorasmie se trouve à Kyuzeligyr et remonte à environ $550 \mathrm{av}$. J.-C. D'autres suivent. Les A. terminent sur la question de l'origine de cette forme architecturale. Nous sommes évidemment tentés de la considérer comme une contribution du centre achéménide à la périphérie. Et pourtant, pensent-ils, il pourrait à l'origine y avoir eu un apport inverse en provenance de l'est. 


\section{AUTEURS}

\section{ASTRID NUNN}

Université de Munich 